\title{
The Prosperity of English Literary Criticism in Multicultural Contexts: Jane Austen's Ideas on Kinships in Emma in the Perspective of Ethical Literary Criticism*
}

\author{
Yan Liu \\ School of International Studies, Binzhou Medical University, Yantai, 264003, China
}

\begin{abstract}
The contemporary English literary criticism has been prosperously developing in multicultural contexts in which various literary criticism theories, such as Ethical literary criticism proposed by Chinese professor Zhenzhao Nie, came into being. The present study attempts, by adopting the theory of ethical literary criticism and an integrated methodology of both textual analysis and logical argumentation, to explore Jane Austen's ethical ideas on kinships in Emma which can be only appreciated in terms of the moral preoccupations that characterize the novelist's peculiar interest in life according to the British critic F.R. Leavis. After a general literature review, the paper presents the major findings of the study, and arrives at a conclusion on Austen's ethical ideas on kinships which are also an inseparable part of Austen's ethical ideas.
\end{abstract}

Index Terms-English literary criticism, multicultural contexts, kinships, Emma, ethical literary criticism

\section{INTRODUCTION}

The contemporary literature in English is flourishing as a result of the development of cultural pluralism and globalization. In such multicultural contexts, it is, necessary and significant for scholars in various backgrounds to conduct English literary criticism from some new perspectives by employing various theories of literary criticism. As one of the new theories, ethical literary criticism proposed by Chinese professor Zhenzhao Nie, involves the analysis of literary works, the relationships between the literary works and the writers, and the analysis of the relationship between literary works and the society from the perspective of ethics. Besides, it emphasizes the writers' and critics' moral responsibilities as well as the moral function of literary works, so as to give correct guidance to readers from the perspective of ethics, and, furthermore, cultivate their elegant aesthetic taste, and enhance moral aesthetic on the part of literary criticism.

As a great novelist and moralist, Jane Austen creates novels not only for the entertainment purpose, but also for the entailment of ethical values. Among her works, Emma is no exception. Emma conveys Austen's unique and mature ethical ideas, just as Leavis stated that "when we examine the formal perfection of Emma, we find that it can be appreciated only in terms of the moral preoccupations that characterize the novelist's peculiar interest in life" (Byrne, 2004, p.56). Highbury in Emma is an organic community embedded with different ranks of people who are restrained by some established codes of behaviors and manners, and it presents a comparatively self-enclosed social organism, with clearly understood ethical norms or principles of stratification when communicating. Austen has a serious moral concern not only about love and marriage, but also other social relationships, such as kinships. Jane Austen enjoys a lively and affectionate family circle which stimulates her to express her strong desire for kinships in her literary creations. Since kinships in Emma are not only pure feelings of human beings, but also serve Austen's writing purpose: to reveal her ethical ideas on kinships, therefore, it is of great significance to explore Jane Austen's ethical ideas on kinships in the perspective of ethical literary criticism.

\section{LITERATURE REVIEW}

Before exploring Jane Austen's ethical ideas on kinships in Emma, it is quite necessary to have a general review of relevant studies on Emma and ethical literary criticism at home and abroad.

A. Studies on Emma

As a work that perfectly represents her genius, Jane Austen's Emma has also been attracting much attention from

\footnotetext{
* The paper is derived from a research project titled "The Construction of English Literary Criticism in Multicultural Contexts"(J12WE22)sponsored by “Humanities and Social Sciences Research Project of Shandong Province Institutions of Higher Education ”(山东省高校人文社会科学研究计划 项目) and a project sponsored by “Medical Humanities Research Center Project of Binzhou Medical University”(13-rwyykt-001) (山东高校人文社 科研究基地滨州医学院医学人文研究中心课题).
} 
scholars and critics worldwide, though ethical criticism on it is not so satisfactory because of various reasons. Sir Walter Scott argued that Emma represented a major new kind of unromantic fiction in 1816. A.C. Bradley described Austen as "a moralist and humorist" (Copeland \& McMaster, 2001, p.233). Reginald Farrer (1917) commented that Emma is "the most complex-and best-of them" (Copeland \& McMaster, 2001, p.233), and anticipated the formalism or new criticism of the mid-twentieth century in his emphasis on the technical mastery of Emma. In Mary Lascelles's book Jane Austen and Her Art (Lascelles, 1939), Jane Austen's use of language, of narrative technique, of timing, and many other artistic issues in Emma were defined and explored with precision and sensitivity. F.R. Leavis (1948) stated that Emma could only be appreciated in terms of the moral preoccupations that characterize the novelist's peculiar interest in life. Therefore, he insisted that readers should grasp the excellence of Emma from the perspective of ethics. Lionel Trilling (1965) made a comment titled as "Emma and the legend of Jane Austen" in his Beyond Culture: Essay on Literature and Learning, he argued that Emma has a moral life as a man had a moral life and Emma was a complex study of self-importance and egotism and malice. D. Lodge (1968) claimed in his Jane Austen's Emma: A Selection of Critical Essays that Emma was the last completely finished product of Austen's maturity. J.F. Burrows (1968) analyzed the themes and art of Emma in Jane Austen's Emma. Marilyn Butler (1975) argued that Austen showed her preference for rationality and inherited moral systems over imagination and individual choice in Emma in her Jane Austen and the War of Ideas.

Chinese scholars also contribute to the studies of Emma. Most of them focus on the analysis of its irony, narrative art, characterization, structure, etc. There are many critical essays on Emma, and in the opinion of most modem critics, it is, of all Jane Austen's novels, the one which most perfectly represents her genius.

\section{B. Studies on Ethical Literary Criticism}

There are intrinsic links between the characteristics of literature and ethics. Many scholars at home and abroad have realized these close links.

After a long period of exile, ethical literary criticism reoccupies academics stealthily in 1990s. Historically, F.R. Leavis states that great novelists show an intense moral interest in life. It is immediately clear as one reads the opening chapter of The Great Tradition that Leavis attempts to set out his conception of the proper relation between form/composition and moral interest/art and life, and refuses to separate art from life, or the aesthetic or formal from the moral. Therefore, he does not think there can be great (literary) art without serious moral purpose. In her Love's Knowledge: Essays on Philosophy and Literature (1990), Martha Nussbaum also points out:

The sense that we are social beings puzzling out, in terms of great moral difficulty, what might be, for us, the best way to live this sense of practical importance, which animates contemporary ethical theory and has always animated much of great literature, is absent from the writings of many our reading literary theorists. (p.169-170)

In China, it is professor Zhenzhao Nie who firstly put forward ethical literary criticism in June, 2004, which has eventually developed into an important issue in the current academic environment and literary critical circle. Hereafter, a series of papers on ethical literary criticism respectively have been issued to illustrate that critics should be responsible for moral re-establishment through literary criticism, so as to recover the moral values in literature.

\section{MAJOR FINDINGS OF AUSTEN’s ETHICAL IDEAS ON KinSHIPS}

When one turns to the families, one notices the curious fact that there are no satisfactory parents in Jane Austen's novels. Instead, she depicts many irresponsible images of parents: in Sense and Sensibility, Emma, and Persuasion, one parent is dead, and the survivor is inadequate. It is also curious for us to learn that there is no image of mother in Emma. Emma is the youngest of the two daughters of a most affectionate, indulgent father, Mr. Woodhouse; she has, in consequence of her sister's marriage, been mistress of the house from a very early period; her mother died too long ago for her to have more than an indistinct remembrance of her caresses; the place of her mother has been supplied by an excellent woman as governess, who has fallen little short of a mother in affection. Jane Fairfax also loses her parents long before; Frank Churchill is adopted by the rich Churchills, though his father is still alive. The study discusses kinships in the novel mainly through the kinship of Emma and her father, Mr. Woodhouse, and the kinship of Emma and her sister, Isabella. With a general survey of the kinships of Emma and her families, Jane Austen's ethical ideas on kinships in Emma can be concluded as the following aspects:

\section{A. Criticism on Traditional Patriarchy and Appeal for Parents' Moral Responsibility}

The image of Mr. Woodhouse who is an irresponsible and dependent father and the image of Emma, who is, instead, competent and independent in Emma reveal Jane Austen's peculiar ethical ideas on kinships between parents and children: it is important for parents to take their moral responsibility to deal with family matters and set a code of ethical requirements towards their children on children's education problems; meanwhile, it is necessary for women to play a positive role in the family.

It is no doubt the image of Mr. Woodhouse is a bold challenge to the traditional image of father in that patriarchal society. It's his ignorance of moral responsibility Mr. Woodhouse should execute that results in his dependent role in family life and the numerous indecent faults committed by Emma. In regard to Austen's criticism on traditional patriarchy, she highly admires Emma's independence as a housemaster, and thus her ethical ideas on kinships can, to 
some degree, reflect her weak feminine consciousness.

Firstly, in Emma, parents' ignorance of moral responsibility and the independence of women can be reflected by the different roles that competent Emma and incompetent Mr. Woodhouse play in their family. In the novel, Jane Austen models a poor, irresponsible and selfish father, Mr. Woodhouse, who exists in name only. Compared to his clever second daughter Emma Woodhouse, Mr. Woodhouse is more like a self-willed child than a respectable father, though he looks like an old gentleman. He is such a foolish man that he considered trifles, such as walking, drinking cereal, consulting pharmacist, and playing card games as his interests. It is Mr. Woodhouse, not Emma Woodhouse, who is complaining day and night, and worrying about the marriage terribly. Instead, Emma is the image of the backbone of the family but not "the Angel in the House". It's Emma Woodhouse, not Mr. Woodhouse, serves as the master of their house Hartfield, manages all the businesses of Hartfield and shows the reader an image of capable mistress. It seems that Mr. Woodhouse is not the leader of the family, but depends on his daughter Emma to a large extent, though it seems no further development of Emma's career.

In this sense, it can be concluded that Jane Austen's view reflects her weak feminine consciousness and going against the traditional ethical view of patriarchy society. She supports that women should play a positive role in family and should participate actively in social activities rather than confine themselves only to a small domestic circle.

Secondly, parents' ignorance of moral responsibility can also be reflected vividly by Mr. Woodhouse's ignorance of children's education. Since Emma's mother died too long age for her to have more than an instinct remembrance of her caresses, so her father, Mr. Woodhouse, is supposed to take the responsibility to educate his children. However, he is almost invalid, and doesn't fulfill his responsibility to educate Emma, and leaves Emma be educated by Miss Taylor, Emma's governess. He, himself, only cares trifles. Although Emma can be taught and taken care of by Miss Taylor, also her intimate friend, she cannot be shaped into a lady without moral faults by such a mild and to some extent a foolish lady who cannot abandon the traditional codes of ethics towards women. Furthermore, nobody can replace a father or a mother's role in children's mind, not to mention that Miss Taylor is only a governess which is regarded as only a "slave" according to the social ethics of that time. Therefore, Emma makes a lot of ridiculous mistakes in the novel due to her moral immaturity during her growing progress. Emma's moral immaturity induces Austen to write even before she began the novel, "I am going to take a heroine whom no one but myself will much like" (Booth, 1983, p.242). At the beginning, Austen introduces the disadvantages of Emma's morality, "The real evils, indeed, of Emma's situation were the power of having rather too much her own way, and a disposition to think a little too well of herself'.(Austen, 2009, p.1). She greatly overestimates her own matchmaking abilities; and she is blind to the dangers of meddling in other people's lives and is often mistaken about the meanings of others' actions. "Indeed, she thinks herself completely happy. The only threat to her happiness, a threat of which she is unaware, is herself: charming as she is, she can neither see her own excessive pride honestly nor resist imposing herself on the lives of others. She is deficient both in generosity and in self-knowledge. She discovers and corrects her faults only after she has almost ruined herself and her closest friends."(Booth, 1983, p.244) There is no doubt that Emma might not have had so many weaknesses on her personality if Mr. Woodhouse takes his moral responsibility as a competent father and supplies Emma a good education. In Jane Austen's eye, responsible parents should supply a good education which is not only intellectually, but also morally. It can not greatly influence one to be a moral person without education intellectually, but it is fatal to a person's development without good taste and moral values. Parents should take their moral responsibly and set a good example for their children.

It is in such exquisite descriptions that Jane Austen creates the image of an incompetent father which is a rebel to the traditional ethical views. With her unique narrative art--irony, Jane Austen gives a scathing satire on that patriarchal society from a perspective of a feminist, and meanwhile, calls on that it is essential for parents to take their moral responsibility and set a code of ethical requirements towards their children, and it is of great significance for women to be the backbone of the family.

\section{B. Desire for Parents' Love}

In Jane Austen's ethical values, she not only emphasizes parents' moral responsibility, but also shows children's deep attachments to parents' love. Although Jane Austen creates an image of an invalid father and no existence of a mother in Emma, it is perhaps this lack of parents' love that makes the heroine deeply desire for parents' love.

Firstly, children are longing for motherly love, which is the greatest one of the world. Since there is no exception that nobody in Emma has a mother, it seems that Jane Austen doesn't emphasize mother's influences upon children, it doesn't matter whether a child has a mother or not. In fact, it is such kind of lack of the character as a mother that reflects children's deep desire for motherly love. It's known that the death of Emma's mother happened too long ago even to be a sad memory. However, Emma wants to enjoy motherly love so as to pour out all kinds of happiness and sadness that lay buried deep in her hearts. Therefore, Austen employs her extraordinary narrative technique to arrange a motherly Miss Taylor as her governess. Emma goes very well with Miss Taylor. They are so imitate that the Author describes their attachment to each other in the novel as the following:

Sixteen years had Miss Taylor been in Mr. Woodhouse's family, less as a governess than a friend, very fond of both daughters, but particularly of Emma. Between them it was more the intimacy of sisters. Even before Miss Taylor had ceased to hold the nominal office of governess, the mildness of her temper had hardly allowed her to impose any restraint; and the shadow of authority being now long passed away, they had been living together as friend and friend 
very mutually attached, and Emma doing just what she liked; highly esteeming Miss Taylor's judgment, but directed chiefly by her own. (Austen, 2009, p.1)

However, after the wedding day of her beloved friend, a gentle sorrow comes to Emma. Emma first sits in mournful thought of any continuance. Austen depicts Emma's affection for Miss Taylor and her sorrow to part from and her as the following:

...She recalled her past kindness--the kindness, the affection of sixteen years--how she had taught and how she had played with her from five years old--how she had devoted all her powers to attach and amuse her in health--and how nursed her through the various illnesses of childhood. A large debt of gratitude was owing here; but the intercourse of the last seven years, the equal footing and perfect unreserved which had soon followed Isabella's marriage, on their being left to each other, was yet a dearer, tenderer recollection. She had been a friend and companion such as few possessed: intelligent, well-informed, useful, gentle, knowing all the ways of the family, interested in all its concerns, and peculiarly interested in herself, in every pleasure, every scheme of hers--one to whom she could speak every thought as it arose, and who had such an affection for her as could never find fault. (Austen, 2009, p.2)

Meanwhile, Miss Taylor is also sad to part from Emma.

...She felt herself a most fortunate woman; and she had lived long enough to know how fortunate she might well be thought, where the only regret was for a partial separation from friends, whose friendship for her had never cooled, and who could ill bear to part with her! (Austen, 2009, p.11)

By describing their attachments to each other, it can be inferred that desiring for the kinship between mother and children is also one of her ethical ideas on kinships. In this way, it is not difficult to understand why Emma gives her motherly love to her nephew, and worries about her nephew's interest when she knows that Harriet targets Mr. Knightley as her marriage partner.

Secondly, children are also longing for fatherly love, which is inseparable with the development of children's mind and body. Emma is no exception, though her father is unsatisfactory. As we have discussed above, she cares much about her father's feeling, even doesn't intend to marry, though she decides to marry her dear love, Mr. Knighley. However, their marriage is based on the condition that Mr. Knightley should settle in Hartfield after marriage. Meanwhile, Mr. Woodhouse also loves Emma, though he doesn't know how to love her, only to spoil and depend on her.

In order to express Emma's great desire for father's real love, the author arranges a fatherly lover, Mr. Knightley, to remind Emma of her mistakes, to help her to correct her faults, to protect and love her. At the beginning of the novel, Emma is immature; in the course of it she moves towards maturity, partly as a result of some rather painful experiences in her relationships with other people, partly as a result of Mr. Knightley's patient, loving and scrupulous guidance to her developing moral sense.

\section{Desire for Sisterly Affections}

Jane Austen concerns much about sisterly affections in Emma. At first, in considering the blood relationship between Emma and her sister, Isabella, their deep affections are natural emotions of human beings and they are in keeping with ethical codes of human beings. Besides, since her mother died years ago and her sister has been married, Emma is apparently not satisfied with this situation, so the deep affections between Emma and her governess companion, Miss Taylor, first of all satisfy Emma's strong desire for sisterly love and motherly love and meanwhile they are also natural outcomes of their sixteen years cultivation. While is a useful companion for Emma to communicate now that Miss Taylor is gone.

Jane Austen vividly describes the deep sisterly affections between Emma and Miss Taylor who also plays a role as a mother. They have stayed together for several years; they enjoy each other, and go well with each other. To Emma, mild Miss Taylor is her best companion and elder sister rather than a strict governess; to Miss Taylor, intelligent Emma is also her best friend and little sister rather than an ignorant pupil. Emma marries Miss Taylor and Mr. Weston by takes advantage of her intelligence, her power, her status as well as the so called talent of matchmaking. The marriage of Miss Taylor seems to be an ideal one and also the best end to her. However, if there is a pity that hits both of Emma and Miss Taylor, that is the fact that they cannot stay together all the time, though they lives not so far from each other and they can visit each other after Miss Taylor's marriage. Emma feels lonely again unless she finds another suitable companion.

Fortunately, such a suitable companion quickly appears, and it is Emma's protégé, Harriet Smith. Emma again invests her sisterly feeling into Harriet. However, her sisterly feeling towards Harriet serves a useful purpose. "Harriet would be useful as a walking companion; she would be a valuable addition to Emma's privileges' in perambulations beyond the grounds of Hartfield. Emma's understanding of Harriet as 'useful' was a logical outcome of companionate relationships that stressed from over substance." (Duckworth, 2002, p. 580) Emma never saw Harriet as a person but as a blank page to be filled in. "Searching for a young woman to 'improve' and 'form' is not unusual in someone of Emma's position. Humble companions offered an opportunity for wealthy women to use their economic and social privilege." (Duckworth, 2002, p.580) Emma makes her greatest effort to refine Harriet's manners and cultivate her taste, and she even seems untied of matching Harriet with Mr. Elton at first, then with Frank Churchill in order to make her live a "happy life". It is also her privilege that makes Harriet seldom lose her own happiness, but finally get it: the union with Mr. Martin, a worthy man.

In summary, Emma vividly conveys Jane Austen's ethical ideas on kinships. She criticizes the traditional patriarchy 
that existed in the family, and she calls on that parents should take their moral responsibility to care for the family as well as cultivate their children; she insists that woman should also play a positive role in the family. On the other hand, Jane Austen's desire for deep affections among family members is vividly shown in the novel, and the reason that why Austen has such ethical ideas on kinships stems mainly from her own family life experiences, such as her energetic family atmosphere and her deep attachment to her sister, Cassandra, which will be another research.

\section{CONCLUSION}

Jane Austen is certainly a serious and interesting moralist. In her Emma. Austen's attitude to morality is not least flexible, but it is less relaxed. However, Jane Austen values true understanding of moral principle for its influence on human development, and in this respect she is aware of the influence of social deprivation on the moral character, at least, in regard to the disadvantages suffered by women in the eighteenth century. the paper makes no efforts to exhaust every aspect of the novel; instead, it just provides one interpretation of it from the perspective of ethical literary criticism in a way that may anticipate a more systematic and comprehensive study.

In multicultural contexts, an exposure of ethics on kinships in Jane Austen's masterpiece Emma from the perspective of ethical literary criticism proves to be of great significance. Since there are a few critics and scholars who study the ethical ideas embedded in Emma, the present research can not only bridge the gap to some extent, and enrich the conventional literary criticism on Jane Austen, but also present us a fresh and comprehensive interpretation of Emma. In addition, a study of Emma from a new perspective, ethical literary criticism, will absolutely enrich the current English literary criticism as a whole, and help a lot in conducting future research practices in the field of English literature, and meanwhile it will make a positive difference in carrying out multicultural construction.

\section{ACKNOWLEDGEMENT}

The study is sponsored by the program "Humanities and Social Sciences Research Project of Shandong Province Institutions of Higher Education"(No.J12WE22) and program "Medical Humanities Research Center Project of Binzhou Medical University"(No.13-rwyykt-001). I also would like to extend my heartfelt thanks to my Professor Juli Wang, for her continuous guidance.

\section{REFERENCES}

[1] Austen, J. (2009). Emma. Shanghai: World Publishing Corporation.

[2] Booth, W.C. (1983). The Rhetoric of Fiction. Chicago: The University of Chicago Press.

[3] Burrows, J.F. (1968). Jane Austen's Emma. Sydney: Sydney University Press.

[4] Butler, M. (1975). Jane Austen and the War of Ideas. Oxford: Clarendon Press.

[5] Byrne, P. (2004). Jane Austen's Emma: A Sourcebook. London: Routledge.

[6] Copeland, E. \& Juliet McMaster. (2001). The Cambridge Companion to Jane Austen. Shanghai: Shanghai Foreign Language Education Press.

[7] Duckworth, A. M. (2002). Emma, by Jane Austen. New York: St. Martin's Press.

[8] Lascelles, M. 1939). Jane Austen and Her Art . Cambridge: Cambridge University Press.

[9] Leavis, F.R. (1948). The Great tradition. London: Chatto \& Windus.

[10] Lodge, D. (1968). Jane Austen's Emma: A Selection of Critical Essays. London: Macmillan.

[11] Nussbaum, M.C. (1990). Love's Knowledge: Essays on Philosophy and Literature. Oxford: Oxford University Press.

[12] Trilling, L. (1965). Beyond Culture: Essay on Literature and Learning. New York: Viking.

[13] Nie, Zhenzhao. (2006). On Ethical Literary Criticism and Moral Criticism. Foreign Literature Studies, 28 (2), 8-17.

[14] Nie, Zhenzhao. (2007). English Literature in the Perspective of Ethical Literary Criticism. Wuhan: Huazhong Normal University Press.

Yan Liu was born in Shandong, China in November 1981. She achieved her Master's degree in English Language and Literature

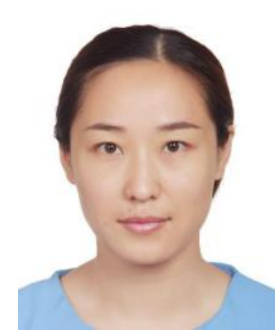
(2010) from Ludong University, China. Her research interests include English literature and culture, Teaching English as a Second Language (TESL)

She has been working in Binzhou Medical University as an English teacher for 10 years, with many papers concerning English language and literature. She is currently accepted as a visitor scholar by the Department of English at The University of Texas at Austin, U.S.A. 